\title{
Ageing trajectory and longevity trade-off in an aphidophagous ladybird, Propylea dissecta (Coleoptera: Coccinellidae)
}

\author{
GeETANJALi MISHRA and OMKAR* \\ Ladybird Research Laboratory, Department of Zoology, University of Lucknow, 226007 Lucknow, India; \\ e-mail: omkaar55@hotmail.com
}

Key words. Coccinellidae, age, ageing trajectory, fecundity, fertility, longevity, Propylea dissecta, trade-off

\begin{abstract}
The ageing trajectory (trend in ageing) and reproduction-longevity trade-off in both sexes of the ladybird Propylea dissecta were studied. The ageing trajectories of both sexes were investigated in terms of reproductive performance, using initial oviposition (egg laying within $24 \mathrm{~h}$ of mating) acting as an indicator of the effect of female age and initial viability (percentage of eggs laid within $24 \mathrm{~h}$ of mating that hatched) of the effect of male age. Ageing trends were sex dependent, with reproductive performance declining later in females than in males. Initial oviposition of females was largely age dependent and the initial viability of males was age dependent but less so than for females. There is a strong trade-off between number of matings and longevity. Statistical analyses reveal that this trade-off results from an early onset of mortality rather than an increase in mortality rate. A minimum lifespan was observed in this ladybird beyond which the longevity did not further decline.
\end{abstract}

\section{INTRODUCTION}

Propylea dissecta (Mulsant), a ladybird of Oriental origin, is commonly found feeding on infestations of Aphis craccivora Koch and Aphis gossypii Glover (Omkar \& Pervez, 2004). It is a polymorphic species with typical (three black streaks on elytra), intermediate (pale black elytral markings) and pale (scarlet without black elytral markings) morphs. This ladybird shows prominent sexual dimorphism with sex-specific black markings on the head and pronotum (Omkar \& Pervez, 2000).

The presence of $P$. dissecta in colonies of the aphids, Aphis affinis del Guercio and Myzus persicae (Sulzer) in Himachal Pradesh (Singh \& Bali, 1993) and of the coconut caterpillar, Opsinia arenosella Walker in Southern India (Pillai \& Nair, 1986) have been previously recorded, but until recently little information was available on this ladybird. Recently, information on the pale and typical morphs of this ladybird were published. While A. gossypii is suitable prey for the pale morph (Pervez \& Omkar, 2004a), A. craccivora is the most preferred prey of the typical morph (Omkar \& Mishra, 2005). The longevity of mated females and males of the pale morph is about 61 and 57 days, respectively, when fed their most suitable prey (Pervez \& Omkar, 2004a). A temperature of $27^{\circ} \mathrm{C}$ resulted in optimum life history attributes (Pervez \& Omkar, 2004b). White light (Omkar et al., 2005) and a 14L: 10D photoperiod (Mishra \& Omkar, 2005) were the most suitable for the development and reproduction of the typical morph.

Mating is necessary for normal oviposition (i.e., laying of clutches of eggs) in $P$. dissecta (Mishra \& Omkar, 2004). Mating is prolonged (4-6 h) and quiescent (Omkar \& Pervez, 2005); the prolonged mating is probably responsible for the mating rate of once per day. This lady- bird oviposits on the underside of substrata regardless of phototaxis and prefers smooth and red coloured surfaces (Omkar \& Mishra, 2003) and preferably at night (Omkar et al., 2004).

The reproductive rate is maintained in this ladybeetle, even when deprived of prey (Omkar \& Pervez, 2003). It shows a triangular age-specific egg laying pattern, indicating the effect of age. The influence of age on reproduction has been documented for both morphs with female age affecting fecundity and male age egg viability (Mishra \& Omkar, 2004; Pervez et al., 2004).

However, despite the studies on this ladybird, the many aspects of ageing and life history trade-offs have been largely ignored. This is despite the fact that this ladybird is a very good model for studying ageing and trade-offs, because of its marked sexual dimorphism (allowing easy segregation).

In ladybirds, the potential effects of ageing on trends (ageing trajectories), and trade-offs have been scarcely studied although these have been extensively studied in other insects, especially, the latter aspect. Ageing trajectories in insects usually follow trends in mortality in a population (Finch, 1990, 1998; Wilson, 1997; Guarente \& Kenyon, 2000; Finch \& Ruvkun, 2001; Robine, 2001) but have not yet been plotted in terms of reproductive parameters, such as fecundity and percent egg viability. Even trade-offs are less studied in ladybirds, though extensively researched in other insects (Rose, 1984; Tatar et al., 1993; Dixon \& Kundu, 1997; Partridge et al., 1999; Sgro \& Partridge, 1999). Thus, in the present study, the ageing trajectories are plotted using reproductive parameters and the existence of a trade-off between longevity and reproductive activity determined using various statistical tests.

\footnotetext{
* Corresponding author.
} 


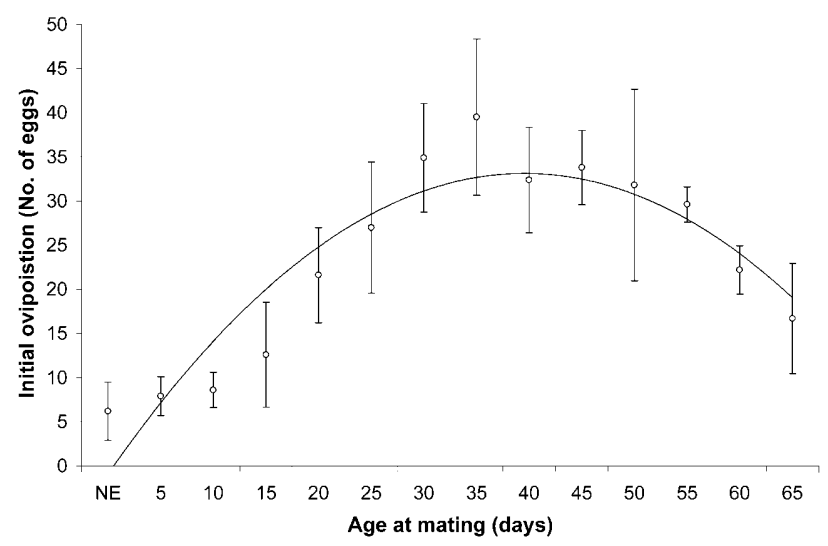

Fig. 1. The initial oviposition of females of $P$. dissecta mated at different ages. The trajectory was fitted using second degree polynomial equation.

\section{MATERIAL AND METHODS}

\section{Laboratory maintenance}

A laboratory culture of $P$. dissecta was established from adults and larvae collected in agricultural fields at Lucknow, India and fed on ad libitum supply of the aphid, Aphis craccivora Koch infesting stems of Dolichos lablab Linnaeus in Petri dishes $(9.0 \times 2.0 \mathrm{~cm})$ kept under constant laboratory conditions: $25 \pm 2{ }^{\circ} \mathrm{C}, 65 \pm 5 \%$ R.H and $14 \mathrm{~L}: 10 \mathrm{D}$. The culture was established in order to ensure a supply of adults for the ageing experiments. Adults of $\mathrm{F}_{2}-\mathrm{F}_{3}$ generations were used in the experiments. All experiments were conducted under the above mentioned abiotic conditions.

\section{Experimental setup}

Study of ageing in males and females

Propylea dissecta was sexed using pronotal marking patterns (Omkar \& Pervez, 2000) and isolated.

Female ageing trajectory. Virgin females of $P$. dissecta of age, 0 [newly emerged, (NE)], 5, 10, 15, 20, 25, 30, 35, 40, 45, $50,55,60$ and 65 days were paired once with a 5-day-old unmated male and then separated. The female was isolated and the occurrence of oviposition within $24 \mathrm{~h}$ of mating (initial oviposition) and percentage egg viability (initial viability) was recorded. Initial oviposition and egg viability (\%) were used to determine effect of age and get an idea of the state of gonadal development. There were ten replicates of each age group.

Male ageing trajectory. Unmated males of age, 0 (NE), 5, 10, $15,20,25,30,35,40,45,50,55,60$ and 65 days were paired once with a 5-day-old virgin female and then the female was isolated. Initial oviposition and initial egg viability was recorded after $24 \mathrm{~h}$. There were ten replicates of each age group.

Data processing. Initial oviposition and initial egg viability were subjected to a one-way ANOVA, with age as the varying factor, using statistical software MINITAB (Minitab, 2003). Ini-

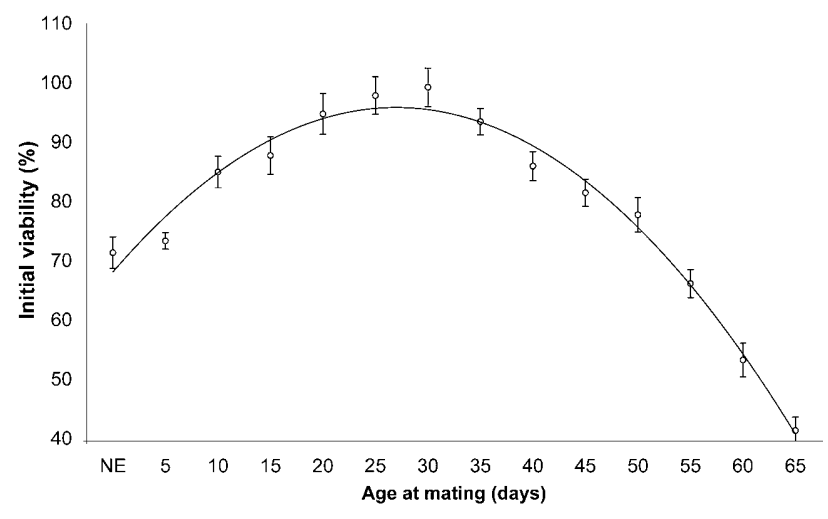

Fig. 2. The initial viability of females of $P$. dissecta mated at different ages. The trajectory was fitted using second degree polynomial equation.

tial oviposition (dependent variable) was subjected to two-way ANOVA (Minitab, 2003) against both sex and age (independent variables). In a similar manner, initial viability as the dependent variable was analyzed.

The factor responding most significantly to the change in female and male age, viz. initial oviposition (from i) and initial viability (from ii) was then regressed on age to obtain the equation describing the ageing trajectories of female and male $P$. dissecta, respectively.

The quadratic regression model $\mathrm{Y}=\mathrm{a}_{0}+\mathrm{a}_{1} \mathrm{X}+\mathrm{a}_{2} \mathrm{X}^{2}$ was used; where, $\mathrm{Y}=$ initial oviposition (for female ageing trajectory) or initial viability (for male ageing trajectory), $\mathrm{X}=$ female age (for female ageing trajectory) or male age (for male ageing trajectory), and $\mathrm{a}_{1}, \mathrm{a}_{2}$ and $\mathrm{a}_{0}$ are constants.

Reproduction-longevity trade-off

Adults were mated $0,5,10,15,20,25,30,35,40$ or 45 times with an inter-mating period of $24 \mathrm{~h}$. They were first mated when they were five-days-old. They were paired daily at $1000 \mathrm{~h}$ in a Petri dish $(9.0 \times 2.0 \mathrm{~cm})$ and allowed to mate once a day. After mating, the adults were separated and the same pair re-paired the next day, subject to experimental requirements. After the required number of matings, adults were isolated and daily provided with an ad libitum supply of $A$. craccivora. Longevity (from adult emergence to death) of both sexes was recorded in ten replicates.

Data processing. Male and female longevity was subjected to one-way ANOVA and correlated with the number of matings using MINITAB. Analysis of onset and rate of ageing in the reproduction-longevity trade-off was done following Tatar et al. (1993). The data on mortality recorded in the various treatments was analyzed in several ways: (1) non-parametric comparison of survival curves, (2) non-parametric comparison of the force of mortality, and (3) estimation of Gompertz parameters with linear regression using statistical software SAS 9.0 (SAS, 2002).

TABLE 1. Parameters (95\% confidence interval) and $\mathrm{R}^{2}$ values, of the ageing trajectories and trade offs of $P$. dissecta fitted by means of second-degree polynomial equations.

\begin{tabular}{ccccc}
\hline Constants & Female ageing trajectory & Male ageing trajectory & Female longevity trade-off & Male longevity trade-off \\
\hline$\alpha_{1}$ & -0.542 & -0.952 & 0.633 & 0.799 \\
$\alpha$ & 9.692 & 12.108 & -14.801 & -17.012 \\
$\beta$ & -10.081 & 56.832 & 140.680 & 140.382 \\
$\mathrm{R}^{2}$ & 0.861 & 0.979 & 0.991 & 0.996 \\
$\mathrm{P}$ & $<0.001$ & $<0.001$ & $<0.001$ & $<0.001$ \\
\hline
\end{tabular}




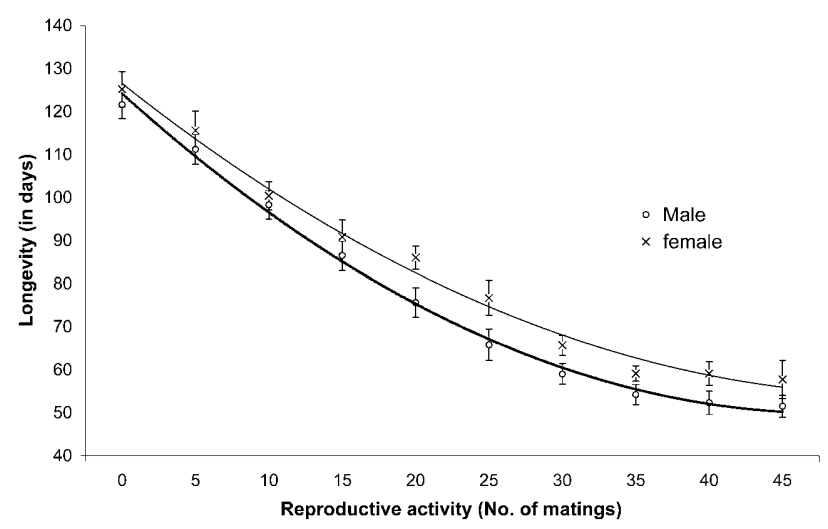

Fig. 3. Trends in the reproductive activity-longevity trade off in male and female $P$. dissecta.

\section{RESULTS}

\section{Ageing trajectories}

Female ageing trajectory

Female age significantly affected initial oviposition $\left(\mathrm{F}_{13,126}=36.69 ; \mathrm{P}<0.001\right)$, which increased up to the age of 35 and thereafter decreased with further increase in female age (Fig. 1). Initial viability also differed significantly with female age though at lower levels $\left(\mathrm{F}_{13,126}=\right.$ 3.83; $\mathrm{P}<0.01)$. The female ageing trajectory fitted by means of a second degree polynomial was statistically significant (Table 1).

\section{Male ageing trajectory}

Newly emerged males did not mate and the females paired with them did not oviposit and were not included in the statistical analysis. Initial egg viability varied significantly $\left(\mathrm{F}_{12,117}=8.45 ; \mathrm{P}<0.001\right)$ with male age, while initial oviposition did not $\left(\mathrm{F}_{12,117}=2.22 ; \mathrm{P}<0.05\right)$. Ageing trajectory of males based on initial egg viability, initially increased up to 30 days and then declined (Fig. 2). The percent egg viabilities were very similar from 25 to 35 days indicating a plateau. The male ageing trajectory fitted by means of a second degree polynomial was statistically significant (Table 1).

A two-way ANOVA indicates that oviposition was influenced both by the sex $\left(\mathrm{F}_{1}=882.30, \mathrm{P}<0.001\right)$ and age $\left(\mathrm{F}_{13}=28.90 ; \mathrm{P}<0.001\right)$ of the individuals. The interaction between these two factors was significant in the case of oviposition $\left(\mathrm{F}_{13,252}=29.10 ; \mathrm{P}<0.001\right)$. Percentage egg viability was also influenced by sex $\left(\mathrm{F}_{1}=302.84\right.$; $\mathrm{P}<$ $0.001)$ and age $\left(\mathrm{F}_{13}=7.36 ; \mathrm{P}<0.001\right)$ of the adults and the interaction between the two independent variables and egg viability is significant $\left(\mathrm{F}_{13,252}=6.34 ; \mathrm{P}<0.001\right)$.

\section{Reproduction-longevity trade-off}

Analysis of variance and correlation

The longevity of unmated males was significantly longer than that of mated males $\left(\mathrm{F}_{9,90}=601.01 ; \mathrm{P}<\right.$ $0.001)$ and was negatively correlated with the number of matings $(\mathrm{r}=-0.96 ; \mathrm{P}<0.001$; Fig. 3 ). Longevity of adult males ranged from $121.6 \pm 3.3$ days for unmated males to $51.5 \pm 2.2$ days for those that mated 45 times.

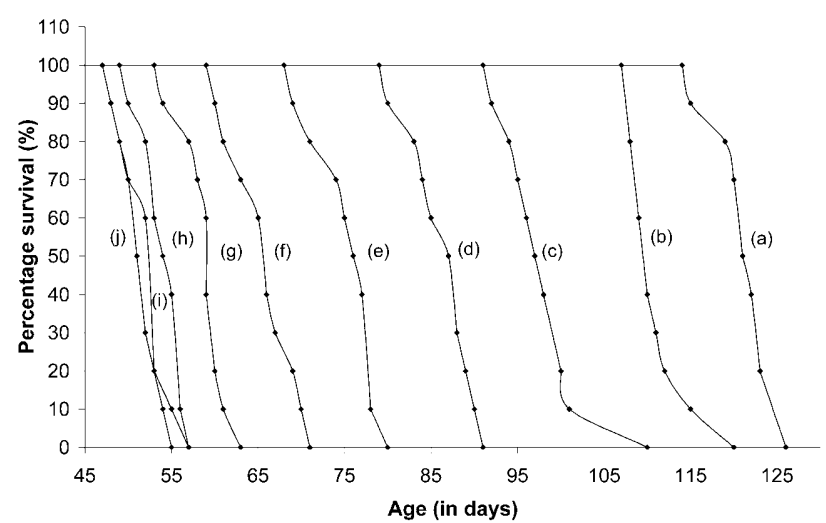

Fig. 4. Graphs depicting onset and rate of senescence of male P. dissecta in relation to (a) 0, (b) 5, (c)10, (d)15, (e) 20, (f) 25, (g) 30, (h) 35, (i) 40, and (j) 45 matings.

The longevity of unmated females was also significantly longer than that of mated females $\left(\mathrm{F}_{9,90}=482.21\right.$; $\mathrm{P}$ $<0.001)$ and was negatively correlated with the number of matings $(\mathrm{r}=-0.96 ; \mathrm{P}<0.001)$. Maximum longevity (125.2 \pm 4.1 days) was attained by unmated females and the minimum $(57.7 \pm 4.4$ days $)$ for those mated 45 times. The data for both males and females was best-fitted using a second degree polynomial (Table 1, Fig. 3).

\section{Survivorship curves}

Non-parametric tests, such as the log-rank test, can be used to summarize differences in the estimated survivorship curves over the entire-study period to determine whether two or more samples could have arisen from identical survivor functions. Overall survivorship was lowest in the highest mating treatment and greatest in unmated treatment in males $\left(\chi^{2}=107.53\right.$; $\mathrm{P}<0.001$; Mantel-Haenszel test; SAS, 2002; Fig. 4). The same trend occurred in female survivorship with the lowest recorded for those subjected to the maximum number of matings and the highest for unmated females $\left(\chi^{2}=132.26\right.$; $\mathrm{P}<$ 0.0001; Fig. 5).

\section{Force of mortality}

Differences in survivorship curves are insufficient for describing differences in the timing, duration and magnitude of mortality between groups. The age-specific mortality $\left(q_{x}\right)$ or force of mortality $\left(\mu_{x}\right)$ for each treatment provide a better insight into the nature of the differences in survivorship. The force of mortality represents the limiting value of age-specific mortality as the age interval becomes infinitesimally small; thus, being independent of the census interval and not bounded by 1.0 . When the census interval is $1 \mathrm{~d}$

$$
\mu_{x} \approx-\ln \left(1-q_{x}\right), \text { and } \operatorname{se}\left(\mu_{x}\right) \approx q_{x} / n_{x}\left(1-q_{x}\right)
$$

where, $\mathrm{x}=$ age, $q_{x}=d_{x} / n_{x}, d_{x}=$ number of individuals dying in the interval, and $n_{x}=$ number of individuals entering the interval (Elandt-Johnson \& Johnson, 1980, p. 143).

In males: In Fig. 6 the force of mortality increases steadily from the first death for a period ranging from approximately $3.5-5.0$ days in all treatments. For the 
TABLE 2. Weighted $\left(\mathrm{n}_{\mathrm{x}}\right)^{1 / 2}$ least squares regression of the initial linear segment of $\ln$ (force of mortality) of male $P$. dissecta. Single model comparison of two straight lines, pairwise comparison with treatment 2 using the backward testing procedure and model $\mathrm{ln}$ $m_{x}=\beta_{0}+\beta_{1} X+\beta_{2} Z+\beta_{3} X Z=E$, where $X$ is age and $Z=0$ for treatment 2 and $Z=1$ for treatments 1, 3-10 (Kleinbaum et al., 1988). Partial F-tests are presented.

\begin{tabular}{|c|c|c|c|c|c|c|c|}
\hline \multirow[b]{2}{*}{ Treatment } & \multicolumn{2}{|c|}{ Parameter estimates } & \multicolumn{3}{|c|}{ Comparison with treatment 2 (5 matings) } & \multicolumn{2}{|c|}{ Mortality rate constants } \\
\hline & Slope b (SE) & Intercept ln a (SE) & Coincidence & Parallel & Intercept & $\begin{array}{l}\text { MRDT }=\ln \\
2 / \mathrm{b}(\text { days })\end{array}$ & $\begin{array}{c}\text { IMR day }^{-1} \\
\left(\times 10^{-3}\right)\end{array}$ \\
\hline $\begin{array}{l}5 \text { matings } \\
\text { (treatment 2) }\end{array}$ & $\begin{array}{l}0.1525 \\
(0.023)\end{array}$ & $\begin{array}{c}-14.600 \\
(0.632)\end{array}$ & - & - & - & 2.57 & 7.54 \\
\hline $\begin{array}{l}10 \text { matings } \\
\text { (treatment } 3 \text { ) }\end{array}$ & $\begin{array}{l}0.1537 \\
(0.056)\end{array}$ & $\begin{array}{c}-16.364 \\
(0.875)\end{array}$ & $\begin{array}{c}9.23 \\
\mathrm{P}<0.001\end{array}$ & $\begin{array}{l}1.02 \\
(\mathrm{NS})\end{array}$ & - & 2.57 & 6.51 \\
\hline $\begin{array}{l}15 \text { matings } \\
\text { (treatment } 4)\end{array}$ & $\begin{array}{l}0.1236 \\
(0.018)\end{array}$ & $\begin{array}{l}-20.383 \\
(1.256)\end{array}$ & $\begin{array}{c}10.25 \\
\mathrm{P}<0.001\end{array}$ & $\begin{array}{l}1.23 \\
(\mathrm{NS})\end{array}$ & - & 2.78 & 7.52 \\
\hline $\begin{array}{l}20 \text { matings } \\
\text { (treatment } 5 \text { ) }\end{array}$ & $\begin{array}{l}0.1579 \\
(0.054)\end{array}$ & $\begin{array}{l}-21.375 \\
(0.231)\end{array}$ & $\begin{array}{c}42.56 \\
\mathrm{P}<0.001\end{array}$ & $\begin{array}{l}1.99 \\
(\mathrm{NS})\end{array}$ & - & 2.54 & 5.23 \\
\hline $\begin{array}{l}25 \text { matings } \\
\text { (treatment 6) }\end{array}$ & $\begin{array}{l}0.1468 \\
(0.078)\end{array}$ & $\begin{array}{c}-14.337 \\
(0.811)\end{array}$ & $\begin{array}{c}78.23 \\
\mathrm{P}<0.001\end{array}$ & $\begin{array}{l}0.85 \\
(\mathrm{NS})\end{array}$ & - & 2.61 & 5.85 \\
\hline $\begin{array}{l}30 \text { matings } \\
\text { (treatment } 7 \text { ) }\end{array}$ & $\begin{array}{l}0.1565 \\
(0.021)\end{array}$ & $\begin{array}{c}-19.166 \\
(1.237)\end{array}$ & $\begin{array}{c}152.03 \\
\mathrm{P}<0.001\end{array}$ & $\begin{array}{l}1.74 \\
(\mathrm{NS})\end{array}$ & - & 2.55 & 3.42 \\
\hline $\begin{array}{l}35 \text { matings } \\
\text { (treatment } 8 \text { ) }\end{array}$ & $\begin{array}{l}0.2651 \\
(0.056)\end{array}$ & $\begin{array}{l}-20.249 \\
(2.13)\end{array}$ & $\begin{array}{c}163.05 \\
\mathrm{P}<0.001\end{array}$ & $\begin{array}{c}2.61 \\
\mathrm{P}<0.01\end{array}$ & $\begin{array}{l}1.23 \\
(\mathrm{NS})\end{array}$ & 2.02 & 3.59 \\
\hline $\begin{array}{l}40 \text { matings } \\
\text { (treatment 9) }\end{array}$ & $\begin{array}{l}0.2392 \\
(0.028)\end{array}$ & $\begin{array}{c}-17.601 \\
(0.962)\end{array}$ & $\begin{array}{c}212.34 \\
\mathrm{P}<0.001\end{array}$ & $\begin{array}{c}3.21 \\
\mathrm{P}<0.01\end{array}$ & $\begin{array}{l}0.65 \\
(\mathrm{NS})\end{array}$ & 2.12 & 2.26 \\
\hline $\begin{array}{l}\text { Lifetime matings } \\
\text { (treatment } 10 \text { ) }\end{array}$ & $\begin{array}{l}0.2564 \\
(0.057\end{array}$ & $\begin{array}{c}-18.558 \\
(0.237)\end{array}$ & $\begin{array}{c}225.58 \\
\mathrm{P}<0.001\end{array}$ & $\begin{array}{c}5.33 \\
\mathrm{P}<0.001\end{array}$ & $\begin{array}{l}1.45 \\
(\mathrm{NS})\end{array}$ & 2.06 & 5.23 \\
\hline $\begin{array}{l}\text { Unmated } \\
\text { (treatment1) }\end{array}$ & $\begin{array}{l}0.1419 \\
(0.009)\end{array}$ & $\begin{array}{c}-30.492 \\
(0.781)\end{array}$ & $\begin{array}{c}5.65 \\
\mathrm{P}<0.01\end{array}$ & $\begin{array}{l}2.04 \\
\text { (NS) }\end{array}$ & - & 2.65 & 9.05 \\
\hline
\end{tabular}

MRDT and IMR stand for mortality rate doubling time and initial mortality rate, respectively.

males that mated from 0 to 30 times, the slight but steady increase in force of mortality was spread over $4.0-5.0$ days. For those that mated 35 or more times, the force of mortality steadily increased over a period of 3.5 days. After this slight increase in mortality, there is a sudden increase in the force of mortality in all the mating treatments for the remaining individuals.

Mortality occurred a considerable amount of time after the last mating. The time after the last mating to the onset of the marked increase in the force of mortality steadily decreased with increased number of matings. Removal of the differential onset of senescence from the graph of mortality resulted in the almost juxtaposition of the graphs of the force of mortality for all treatments. The initial portions of the graphs of the force of mortality in all treatments were thus parallel and coincident indicating a similar force of mortality in the initial stages of increase in mortality. Thus, these plots of the forces of mortality indicate that the rate of senescence is almost constant and it is the onset of senescence that changes with reproductive activity.

In females: The force of mortality in females increased from the time of the first death for a period ranging from approximately 4.0-6.0 days in all treatments (Fig. 8). In treatments involving 0 to 25 matings there was a slight steady increase in the force of mortality over a period of 5.0-6.0 days. This was, however, not seen in the treatment that involved 20 matings. In groups in which there were 20 or 35 or more matings, the force of mortality steadily increased over a period of 4.0-5.0 days. After this slight increase in mortality there was a sudden increase in the force of mortality in all treatments. Mortality only occurred after a considerable amount of time had elapsed since the last mating. Age at onset of mortality decreased with increased number of matings.

The initial sections of the graphs of force of mortality recorded in each of the treatments are approximately parallel and coincident indicating similar forces of mortality in the initial stages of the onset of mortality. Thus, these plots of the force of mortality indicate that the rate of senescence is almost constant and it is the onset of senescence that changes with reproductive activity.

\section{Gompertz analysis}

The data were analyzed using the Gompertz model because of its simplicity and previous use in such studies (Tatar et al., 1993), although its application presents a difficulty. The trajectories of $\ln \mu_{x}$ are not linear as assumed by the Gompertz model, i.e., age-specific mortality does not increase at a constant rate.

It is postulated following Gompertz that adult mortality increases exponentially at a constant rate " $b$ " starting from some initial level " $a$ " such that $\mu_{x}=a e^{b x}$. Plots of $\ln$ $\mu_{x}$ against age $x$ are linear with slope $b$ and intercept $\ln a$ and least-squares linear regression are used to estimate these parameters. Parallel non-coincidental plots have similar rates of change in age-specific mortality (b) but differ in initial mortality rates (a). Plots that diverge in 


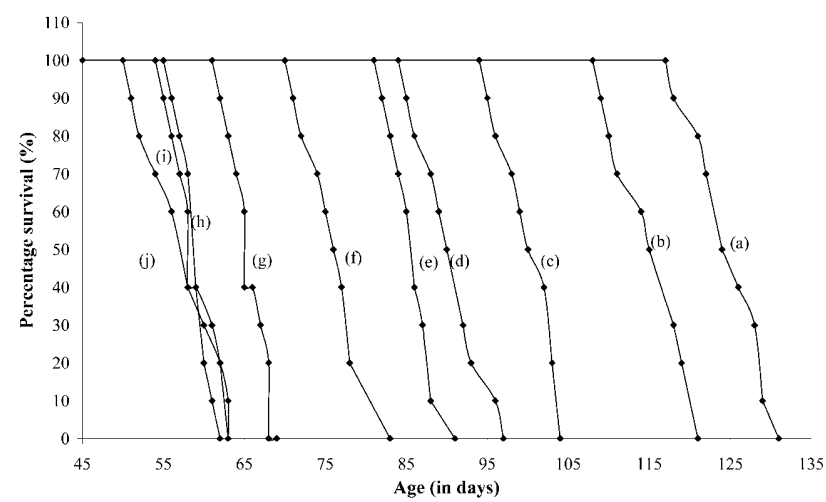

Fig. 5. Graphs depicting onset and rate of senescence of male P. dissecta in relation to (a) 0, (b) 5, (c)10, (d)15, (e) 20, (f) 25, (g) 30, (h) 35, (i) 40, and (j) 45 times.

slope have different rates of change in age-specific mortality. The coefficient for the rate of change in agespecific mortality, $(b)$ is an index of the rate of demographic senescence and changes in this value are a way to quantify experimental effects on the rate of senescence

In males: Based on visual inspection the log force of mortality was assumed to be linear in the initial 7 days after start of mortality in the males subjected to the different mating treatments. The initial segments of all these graphs appear parallel (Fig. 7). The $\ln m_{x}$ plot of the higher mating treatments differs from the lower ones by a shift, usually to the left. The slope of the graph for unmated males increases less rapidly than that of the graph for the mated treatments. These observations were verified by estimating and comparing the Gompertz parameters for initial linear segments with least-squares regression and a single-model test of coincidence (Kleinbaum et al., 1988), weighted by $\mathrm{n}_{\mathrm{x}}{ }^{1 / 2}$ to correct for the dependence of variance on sample size (Table 2).

The rate of demographic senescence is not changed by the manipulation of mating among mated males. The mortality rate doubling times $(\mathrm{MRDT}=\ln 2 / \mathrm{b})$ among mated

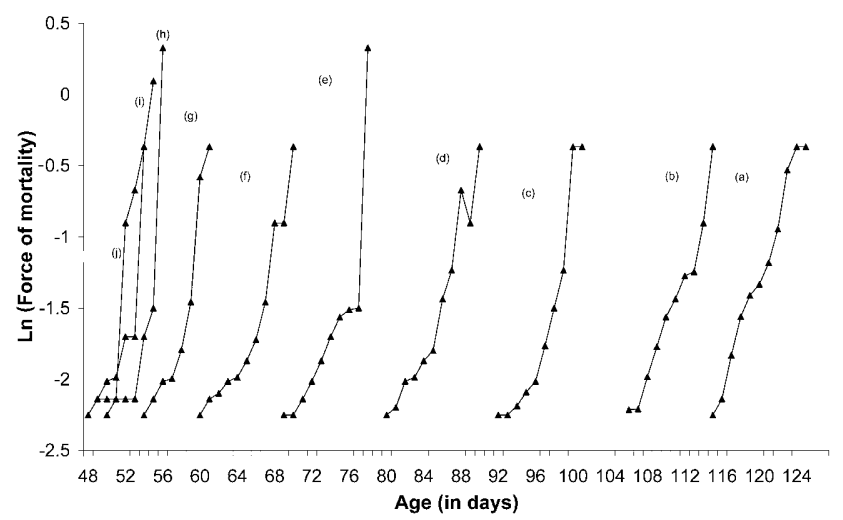

Fig. 7. Natural $\log$ of force of mortality in males of $P$. dissecta that were mated (a) 0, (b) 5, (c)10, (d)15, (e) 20, (f) 25, (g) 30, (h) 35, (i) 40, and (j) 45 times.

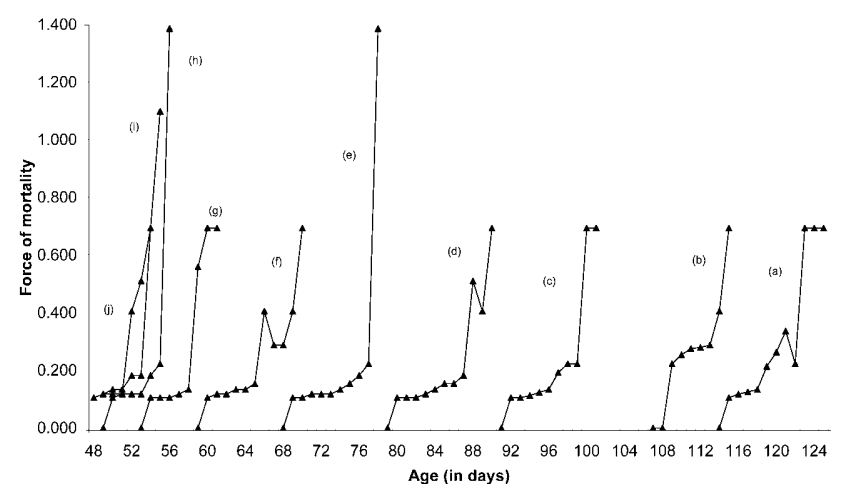

Fig. 6. Force of mortality in males of $P$. dissecta that were mated (a) 0, (b) 5, (c)10, (d)15, (e) 20, (f) 25, (g) 30, (h) 35, (i) 40 , and (j) 45 times.

as well as unmated males was $2.02-2.78$ days. The initial mortality rate differed between treatments (Table 2 ).

In females: Based on visual inspection, the log force of mortality was assumed to be linear in the initial 6 days after the start of mortality in females in all the treatments. The initial segments of these graphs appear to be almost parallel in all treatments (Fig. 9). A shift to the left of the graphs usually differentiates individuals with a higher number of matings from the others. The slope for the unmated females increased less rapidly than that for mated females, however not by very much. These observations were verified statistically.

The rate of demographic senescence is not changed by the incidence of mating. The mortality rate doubling time $(\mathrm{MRDT}=\ln 2 / \mathrm{b})$ among mated as well as unmated females was $1.90-2.56$ days. The initial mortality rate differed between treatments (Table 3 ).

\section{DISCUSSION}

Initial oviposition in females and initial egg viability in males were affected by ageing in $P$. dissecta. Initial egg viability was, however, not solely influenced by male age and only at low levels of significance by female age. The decline in egg viability with female age may be due to a

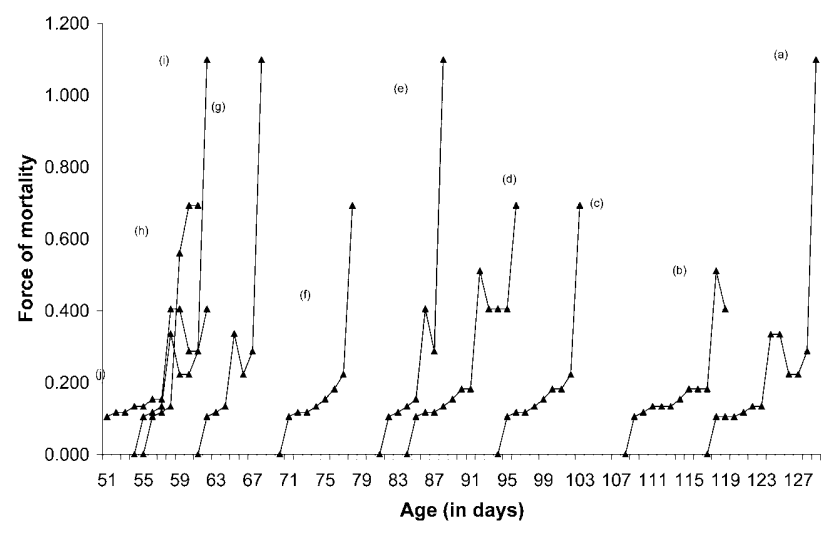

Fig. 8. Force of mortality in females of $P$. dissecta that were mated (a) 0, (b) 5, (c)10, (d) 15, (e) 20, (f) 25, (g) 30, (h) 35, (i) 40 , and (j) 45 times 


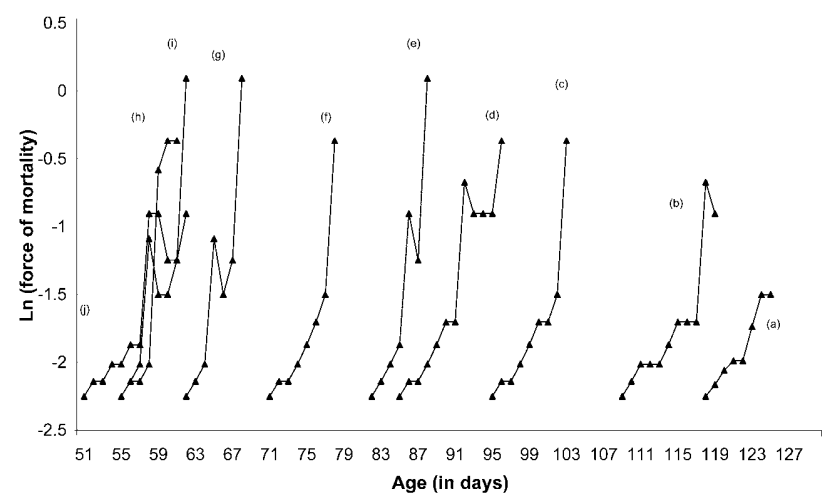

Fig. 9. Natural $\log$ of force of mortality in females of $P$. dissecta that were mated (a) 0, (b) 5, (c) 10 , (d) 15 , (e) 20, (f) 25, (g) 30, (h) 35, (i) 40, and (j) 45 times.

decline in the activity of the musculature of the female genital tract and consequent decreased motility of sperm.

The variation in fertility and viability with age supports evolutionary theories of ageing that the rates of ageing evolve differentially in sexes (Williams, 1957; Hamilton, 1966; Kirkwood, 1977; Partridge \& Barton, 1993). Fertility and viability can thus be used as indicators of ageing for both female and male ladybirds.

A gradual decline in rate of ageing (plateau formation), reported in mortality trajectories of other insects (Carey et al., 1992; Curtsinger et al., 1992; Tatar et al., 1993), was not found in the oviposition and viability trajectories up to the age of 65 days in the present study. A study of the rate of ageing up to the ages of 120-130 days (maximum longevity of unmated adults) may provide a further insight and reveal a plateau.

The trajectories are not synchronized in the sexes, as the decline in female reproductive ability started after 35 days and in males after 30 days, which indicate that the ageing rates differ between sexes. The later senescence in females is interesting since in a majority of insects males remain fertile for longer than females (Robine, 2001).

Cost of reproduction in terms of mortality is evident in adults of $P$. dissecta when reproduction is manipulated. This trade-off has previously been reported in other insects (Partridge \& Farquhar, 1981; Rose, 1984; Roitberg, 1989; Babu \& Ananthakrishnan, 1993; Tatar et al., 1993; Dixon \& Kundu, 1997). Similar findings in ladybirds are, however, not common though in general unmated adults survive longer than mated ones (Rawat \& Modi, 1969; Agarwala \& Choudhuri, 1995). Fecundity is also negatively correlated with longevity in the ladybird, Adalia bipunctata (Kariluoto, 1980). The almost universality of this finding suggests there is a trade-off between current reproduction and other life history traits (Barnes $\&$ Partridge, 2003). Gompertz equation parameters are often used to estimate and quantify the rate of change of age-specific mortality, which is considered to be an index of demographic senescence (Finch et al., 1990; Johnson, 1990; Promislow, 1991; Tatar et al., 1993).

TABLE 3. Weighted $\left(\mathrm{n}_{\mathrm{x}}\right)^{1 / 2}$ least squares regression of the initial linear segment of $\ln$ (force of mortality) of female $P$. dissecta. Single model comparison of two straight lines, pairwise comparison with treatment 2 using the backward testing procedure and model $\ln m_{x}=\beta_{0}+\beta_{1} X+\beta_{2} Z+\beta_{3} X Z=E$, where $X$ is age and $Z=0$ for treatment 2 and $Z=1$ for treatments 1, 3-10 (Kleinbaum et al., 1988). Partial F-tests are presented.

\begin{tabular}{|c|c|c|c|c|c|c|c|}
\hline \multirow[b]{2}{*}{ Treatment } & \multicolumn{2}{|c|}{ Parameter estimates } & \multicolumn{3}{|c|}{ Comparison to treatment 2 (5 matings) } & \multicolumn{2}{|c|}{ Mortality rate constants } \\
\hline & Slope b (SE) & $\begin{array}{l}\text { Intercept ln a } \\
\text { (SE) }\end{array}$ & Coincidence & Parallel & Intercept & $\begin{array}{l}\text { MRDT }=\ln \\
2 / \mathrm{b} \text { (Days) }\end{array}$ & $\begin{array}{c}\text { IMR day }^{-1} \\
\left(\times 10^{-3}\right)\end{array}$ \\
\hline $\begin{array}{l}5 \text { matings } \\
\text { (treatment 2) }\end{array}$ & $\begin{array}{l}0.1692 \\
(0.047)\end{array}$ & $\begin{array}{c}-18.6210 \\
(3.8652)\end{array}$ & - & - & - & 2.47 & 7.58 \\
\hline $\begin{array}{l}10 \text { matings } \\
\text { (treatment } 3 \text { ) }\end{array}$ & $\begin{array}{l}0.1775 \\
(0.097)\end{array}$ & $\begin{array}{l}-20.2800 \\
(2.3145)\end{array}$ & $\begin{array}{c}3.21 \\
(\mathrm{P}<0.001)\end{array}$ & $\begin{array}{l}0.23 \\
(\mathrm{NS})\end{array}$ & - & 2.42 & 6.23 \\
\hline $\begin{array}{l}15 \text { matings } \\
\text { (treatment } 4)\end{array}$ & $\begin{array}{l}0.1878 \\
(0.023)\end{array}$ & $\begin{array}{c}-18.5070 \\
(3.457)\end{array}$ & $\begin{array}{c}4.12 \\
(\mathrm{P}<0.001)\end{array}$ & $\begin{array}{l}1.11 \\
(\mathrm{NS})\end{array}$ & - & 2.37 & 6.84 \\
\hline $\begin{array}{l}20 \text { matings } \\
\text { (treatment } 5 \text { ) }\end{array}$ & $\begin{array}{l}0.1657 \\
(0.231)\end{array}$ & $\begin{array}{c}-31.6201 \\
(1.2391)\end{array}$ & $\begin{array}{c}9.26 \\
(\mathrm{P}<0.001)\end{array}$ & $\begin{array}{l}0.14 \\
(\mathrm{NS})\end{array}$ & - & 2.49 & 6.23 \\
\hline $\begin{array}{l}25 \text { matings } \\
\text { (treatment } 6)\end{array}$ & $\begin{array}{l}0.1602 \\
(0.011)\end{array}$ & $\begin{array}{c}-17.3190 \\
(0.8564)\end{array}$ & $\begin{array}{c}9.68 \\
(\mathrm{P}<0.001)\end{array}$ & $\begin{array}{l}0.51 \\
(\mathrm{NS})\end{array}$ & - & 2.52 & 5.66 \\
\hline $\begin{array}{l}30 \text { matings } \\
\text { (treatment } 7 \text { ) }\end{array}$ & $\begin{array}{l}0.2798 \\
(0.147)\end{array}$ & $\begin{array}{c}-23.1140 \\
(4.1702)\end{array}$ & $\begin{array}{c}15.26 \\
(\mathrm{P}<0.001)\end{array}$ & $\begin{array}{c}5.61 \\
(\mathrm{P}<0.001)\end{array}$ & & 1.97 & 7.14 \\
\hline $\begin{array}{l}35 \text { matings } \\
\text { (treatment } 8 \text { ) }\end{array}$ & $\begin{array}{l}0.2069 \\
(0.098)\end{array}$ & $\begin{array}{l}-29.6480 \\
(3.124)\end{array}$ & $\begin{array}{c}11.48 \\
(\mathrm{P}<0.001)\end{array}$ & $\begin{array}{c}6.32 \\
(\mathrm{P}<0.001)\end{array}$ & $\begin{array}{l}1.35 \\
\text { (NS) }\end{array}$ & 2.27 & 7.32 \\
\hline $\begin{array}{l}40 \text { matings } \\
\text { (treatment 9) }\end{array}$ & $\begin{array}{l}0.2711 \\
(0.064)\end{array}$ & $\begin{array}{c}-19.5700 \\
(1.9658)\end{array}$ & $\begin{array}{c}13.57 \\
(\mathrm{P}<0.001)\end{array}$ & $\begin{array}{c}6.94 \\
(\mathrm{P}<0.001)\end{array}$ & $\begin{array}{c}2.99 \\
(\mathrm{P}<0.05)\end{array}$ & 2.00 & 4.12 \\
\hline $\begin{array}{l}\text { Lifetime matings } \\
\text { (treatment } 10 \text { ) }\end{array}$ & $\begin{array}{l}0.2987 \\
(0.091)\end{array}$ & $\begin{array}{l}-9.3481 \\
(1.0024)\end{array}$ & $\begin{array}{c}13.21 \\
(\mathrm{P}<0.001)\end{array}$ & $\begin{array}{c}5.82 \\
(\mathrm{P}<0.001)\end{array}$ & $\begin{array}{l}0.86 \\
\text { (NS) }\end{array}$ & 1.90 & 5.65 \\
\hline $\begin{array}{l}\text { Unmated } \\
\text { (treatment1) }\end{array}$ & $\begin{array}{l}0.1548 \\
(0.023)\end{array}$ & $\begin{array}{c}-23.1260 \\
(2.3501)\end{array}$ & $\begin{array}{c}5.62 \\
(\mathrm{P}<0.001) \\
\end{array}$ & $\begin{array}{l}1.17 \\
(\mathrm{NS}) \\
\end{array}$ & - & 2.56 & 10.23 \\
\hline
\end{tabular}

MRDT and IMR stand for mortality rate doubling time and initial mortality rate, respectiv ely. 
Gompertz estimates and parametric analyses reveal that this trade-off is caused by a change in initial mortality rate, i.e. onset of ageing, rather than a difference in the rate of change of age-specific mortality (rate of ageing). Almost similar slopes in males and females indicate lack of differences in the rates of ageing, regardless of mating activity. Unmated adults of the pulse beetle, Callosobruchus maculatus (Fabricius), differed from mated adults in that the mortality rate of the latter was almost double that of the former (Tatar et al., 1993). In P. dissecta, no such changes were evident and the rates of ageing were similar in all treatments. In the aphagous $C$. maculatus, it is possible that the decline is probably a result of nutrient exhaustion rather than a progressive loss of physiological homeostasis. In aphids too the cessation of feeding and the resultant rapid depletion of nutrient reserves in those that mate may account for the early onset of ageing in those individuals (Dixon \& Kundu, 1997). In $P$. dissecta, which feeds continuously, the decrease in longevity with increased reproductive activity in females, is a combined result of energy loss in mating and its subsequent utilization in oviposition, whereas in males it is probably a result of energy loss due to mating. Our results, based on survivorship curves, advance the analyses of the cost of reproduction.

The almost similar longevities of adults mated 35, 40 and 45 times, despite differential energy expenditure in mating, possibly results from a minimum lifespan for a healthy individual kept under optimal conditions (Robine, 2001). That is, there is a certain minimum age expectancy.

Thus, it seems that the different levels of sexual activity did not influence the rate of ageing but its onset. This was found to be the case in the aphid, Cavariella aegopodii (Dixon \& Kundu, 1997). This is, however, contrary to the findings on Drosophila, where it is an acceleration in the ageing rate that leads to a decrease in longevity (Rose, 1984; Simmons \& Bradley, 1997; Partridge et al., 1999; Sgro \& Partridge, 1999).

An interesting point that needs to be emphasized is the high incidence of mating in $P$. dissecta; at no time was a male reluctant to mate with a female. However, males that were kept with females throughout life (unpubl. results) did not mate as frequently, i.e. once every $24 \mathrm{~h}$. The readiness of male $P$. dissecta to mate if kept on their own for a short period is very evident, which makes $P$. dissecta a very suitable model for investigating reproductive biology.

ACKNOWLEDGEMENTS. Authors are thankful to A.F.G. Dixon, School of Biological Sciences, University of East Anglia, Norwich, UK, for language improvement and T. Tregenza, Centre for Ecology and Conservation, University of Exeter in Cornwall, United Kingdom for making available the literature required for this study. GM is thankful to the Council of Science and Industrial Research, New Delhi for the award of a fellowship.

\section{REFERENCES}

Agarwala B.K. \& Choudhuri M.S. 1995: Use of alternative foods in the rearing of aphidophagous ladybeetle, Menochilus sexmaculatus Fabr. Entomon 20: 19-23.

Babu A. \& Ananthakrishnan T.N. 1993: Predatory efficiency, reproductive potential, and bioenergetics of Coccinella transversalis F. and Menochilus sexmaculatus F. (Coleoptera: Coccinellidae) in relation to aphid (Homoptera: Aphididae) prey quality. Phytophaga 5: 121-133.

Barnes A. \& Partridge L. 2003: Costing reproduction. Anim. Behav. 66: 199-204.

Carey J.R., Liedo P., Orozeo D. \& Vaupel J.W. 1992: Slowing of mortality rates at older ages in large medfly cohorts. Science 258: 457-461.

Curtsinger J.W., Fukui H.H., Townsend D.R. \& Vaupel J.W. 1992: Demography of genotypes: failure of the limited lifespan a paradigm in Drosophila melanogaster. Science 258: 461-463.

Dixon A.F.G. \& Kundu R. 1997: Trade-off between reproduction and length of adult life in males and mating females of aphids. Eur. J. Entomol. 94: 105-109.

ElandT-Johnson R. \& Johnson N.L. 1980: Survival Models and Data Analysis. Wiley, New York, 457 pp.

Finch C.E. 1990: Longevity, Senescence and the Genome. University of Chicago Press, Chicago, 938 pp.

FINCH C.E. 1998: Variations in senescence and longevity include the possibility of negligible senescence. J. Gerontol. (A, Biol. Sci. Med. Sci.) 53: B235-B239.

Finch C.E. \& Ruvkun G. 2001: The genetics of aging. Annu. Rev. Genom. Human Gen. 2: 435-462.

Finch C.E., Pike M.C. \& WitTen M. 1990: Slow mortality rate accelerations during aging in some animals approximate that of humans. Science 249: 902-905.

Guarente L. \& KenYon C. 2000: Genetic pathways that regulate ageing in model organisms. Nature 408: 255-262.

HAMiLton W.D. 1966: The moulding of senescence by natural selection. J. Theor. Biol. 12: 12-45.

JOHNSON T.E. 1990: Increased life-span of age-1 mutants in Canorhabditis elegans and lower Gompertz rate of aging. Science 249: 908-912.

KARILUOTO K.T. 1980: Survival and fecundity of Adalia bipunctata (Coleoptera: Coccinellidae) and some predatory insect species on an artificial diet and a natural prey. Ann. Entomol. Fenn. 46: 101-106.

KIRKwOod T.B.L. 1977: Evolution of ageing. Nature 270: 301-304.

Kleinbaum D.G., Kupper L.L. \& Muller K.K. 1988: Applied Regression Analysis and Other Multivariable Methods. PWS, Kent, Boston, 718 pp.

Minitab 2003: Minitab 13.1. Minitab, Inc. Philapdelphia, USA.

Mishra G. \& OMKAR 2004: Influence of parental age on reproductive performance of an aphidophagous ladybird, Propylea dissecta (Mulsant). J. Appl. Entomol. 128: 605-609.

Mishra G. \& OMKAR 2005: Influence of components of light on the life attributes of an aphidophagous ladybird, Propylea dissecta (Coleoptera: Coccinellidae). Int. J. Trop. Insect Sci. 25: 32-38.

OMKaR \& Mishra G. 2003: Ovipositional orientation of an aphidophagous ladybeetle, Propylea dissecta (Mulsant). Insect Sci. Applic. 23: 211-219.

OMKar \& Mishra G. 2005: Preference-performance of a generalist predatory ladybird: a laboratory study. Biol. Cont. 34: 187-195. 
Omkar \& Pervez A. 2000: Sexual dimorphism in Propylea dissecta (Mulsant), (Coccinellidae: Coleoptera). J. Aphidol. 14: 139-140.

OmKar \& Pervez A. 2003: Influence of prey deprivation on biological attributes of pale morphs of the ladybeetle, Propylea dissecta (Mulsant). Insect Sci. Applic. 23: 143-148.

OmKar \& Pervez A. 2004: Predaceous coccinellids in India: Predator-prey catalogue. Orient. Insects 38: 27-61.

OMKar \& Pervez A. 2005: Mating behavior of an aphidophagous ladybird beetle, Propylea dissecta (Mulsant). Insect Sci. 12: 37-44.

OmKar, Mishra G., Srivastava. S. \& Gupta A.K. 2004: Ovipositional rhythmicity in ladybird beetles (Coleoptera: Coccinellidae): a laboratory study. Biol. Rhy. Res. 35: 277-287.

OMKar, Mishra G. \& Singh K. 2005: Effect of different wavelengths of light on the life attributes of two aphidophagous ladybirds. Eur. J. Entomol. 102: 33-37.

PARTRIDGe L. \& BARTON N.H. 1993: Evolution of aging: testing the theory using Drosophila. Genetics 91: 89-98.

Partridge L. \& Farquhar M. 1981: Sexual activity reduces life span of male fruit flies. Nature 294: 580-582.

Partridge L., Prowse N. \& Pignatelli P. 1999: Another set of responses and correlated responses to selection on age at reproduction in Drosophila melanogaster. Proc. R. Soc. Lond. (B) 266: 255-261.

Pervez A. \& Omkar 2004a: Prey dependent life attributes of an aphidophagous ladybird beetle, Propylea dissecta (Mulsant). Biocont. Sci. Tech. 14: 385-396.

Pervez A. \& Omkar 2004b: Temperature dependent life attributes of an aphidophagous ladybird beetle, Propylea dissecta (Mulsant). Biocont. Sci. Tech. 14: 587-594.

Pervez A., OmKar \& Richmond A.S. 2004: The influence of age on reproductive performance of a predatory ladybird beetle, Propylea dissecta. J. Insect Sci. 4(22): 1-8.
Pillai G.B. \& Nair K.R. 1986: Addition to the natural enemy complex of the coconut caterpillar, Opisinia arenosella Wlk. J. Plant. Crops 14: 138-140.

PRomislow D.E. 1991: Senescence in natural populations of mammals: a comparative study. Evolution 45: 1869-1887.

Rawat R.R. \& Modi B.N. 1969: Studies on Nephus regularis (Coleoptera: Coccinellidae) as a predator of striped mealybug in Madhya Pradesh. Ann. Entomol. Soc. Am. 62: 953-956.

RoBine J.M. 2001: A new biodemographic model to explain the trajectory of mortality. Exp. Geron. 36: 899-914.

RoITBERG B.D. 1989: The cost of reproduction in rosehip flies Rhagoletis basiola eggs are time. Evol. Ecol. 3: 183-188.

Rose M.R. 1984: Laboratory evaluation of postponed senescence in Drosophila melanogaster. Evolution 38: 1004-1010.

SAS 2002: SAS Statistical Software, Version 9.00. SAS Institute Inc., Cary, North Carolina, USA.

Sgro C.M. \& PArtridge L. 1999: A delayed wave of death from reproduction in Drosophila. Science 286: 2521-2524.

Simmons F.H. \& Bradley T.J. 1997: An analysis of resource allocation in response to dietary yeast in Drosophila melanogaster. J. Insect Physiol. 43: 779-780.

SingH K.C. \& BALI G. 1993: New record of coccinellid predators on aphid (Aphis affinis and Myzus persicae) in Japanese mint (Mentha arvensis subsp. haplocalyx var. piperascens) and Egyptian henbane (Hyoscyamus muticus). Indian $J$. Agric. Sci. 63: 313-314.

Tatar M., Carey J.R. \& Vaupel J.W. 1993: Long-term cost of reproduction with and without accelerated senescence in Callosobruchus maculatus: Analysis of age-specific mortality. Evolution 47: 1302-1312.

WiLliams G.C. 1957: Pleiotropy, natural selection and the evolution of senescence. Evolution 11: 398-411.

WILSON J.B. 1997: An evolutionary perspective on the "death hormone" hypothesis in plants. Physiol. Plant. 99: 511-516.

Received June 14, 2004; revised and accepted September 7, 2005 